Type of the Paper (Article)

\title{
A Study of ZVS, ZCS and ZVZCS techniques in Reducing the Energy Loss and Improving the Soft Switching Range
}

\author{
Ratil Ashique ${ }^{1}$, Zainal Salam ${ }^{2}$ \\ 1 Affiliation 1; Department of EEE, Green University of Bangladesh, ratil.eee05@gmail.com \\ 2 Affiliation 2; Department of EEE, University Technology Malaysia, zainals@fke.utm.my \\ * Correspondence: ratil.eee05@gmail.com; Tel.: +8801773590010
}

\begin{abstract}
This paper presents a comparative analysis of the ZVZCS soft switching technique with the ZVS and the ZCS counterpart. The generalization of the voltage-current crossover or the energy loss factor obtained from simulation of the prototype converter shows that the ZVZCS significantly reduces the loss and helps to improve the efficiency of the converter as compared to the ZVS or the ZCS. On the other hand, it is also found that the soft switching range of operation of the ZVS and the ZCS are largely affected by the maximum switch voltage and switch current respectively. In contrary, these factors have a negligible effect on the ZVZCS operation which results in an extended range of soft switching operation. Additionally, a detailed LTPICE simulation is performed for selected ZVS, ZCS and ZVSCS topologies from the recent literature and the switching losses in the main switches of the converters are measured. It is observed that the energy losses in the ZVZCS mode are reduced on average by approximately $26 \%$ at turn on and $20 \%$ at the turn off as compared to the ZVS and the ZCS. Besides, the low standard deviation in this mode confirms a stable low loss profile which renders extended soft switching range. An experimental test is also conducted by building the prototype converter to verify the simulation results. It is found that the switching losses are minimum while the converter is operated in the ZVZCS mode. Besides, the efficiency drop remains consistently low as compared to the ZVS and the ZCS in the whole operating range. Resultantly, the simulation and the experimental results are both found to be consistent.
\end{abstract}

Keywords: ZVZCS, ZVS, ZCS, soft switching, soft switching range

\section{Introduction}

The switching losses are one of the primary contributors to the efficiency reduction of the dc-dc converters. This is particularly critical when the converter is operated at low power level and high switching frequency. To alleviate this problem, various soft switching techniques are being proposed [1-15], which includes the zero voltage switching (ZVS), zero current switching (ZCS) and zero voltage zero current switching (ZVZCS). When operating in these modes, the voltage and current transients are manipulated to reduce the voltage-current crossover, otherwise defined as the switching loss. In the ZVS case, the voltage transients at the turn on and turn off instants are restricted to reduce large crossover with the current. On the other hand, for the ZCS, the current transients rather than the voltage are controlled in order to achieve the same purpose. In the ZVZCS [16-22], both the voltage and current transients are simultaneously controlled to reduce the crossover at both the turn on and turn off instants. This results in significant improvement in the switching losses, hence higher efficiency. Particularly, this is a direct consequence of simultaneous manipulation of both the voltage and the current transients to reduce the crossover losses. However, the existing papers [16-22] do not explicitly cover this issue and analyze the ZVZCS from this point of view. Hence, considering these factors, it would be interesting to investigate the relative standing of the ZVZCS to the other soft switching techniques (i.e. the ZVS and ZCS) in terms of loss reduction capability and 
soft switching range of operation. Eventually, a generic conclusion regarding the superiority or inferiority of the ZVZCS technique over the ZVS and the ZCS can be reached. Additionally, this would further enhance the understanding of the soft switching techniques and their implementation into the dc-dc converters.

Based on this literary gap, this paper presents a generalized analysis to investigate the relative status of the ZVZCS over the ZVS and the ZCS techniques. For this purpose, the switching transients of the ZVS, ZCS and the ZVZCS are linearized from the simulation results of the prototype converter. A geometrical analysis to determine the crossover energy and the soft switching range of operation is then performed as demonstrated in Section II and III respectively. It is found that the crossover energy is reduced in the ZVZCS as compared to the ZVS and the ZCS. In addition, the dependency of the soft switching performance on the input voltage and the switch current is lowered. Next, the simulation for comparative analysis is performed. A large number of converters are selected (to retain a large sample size) for simulation and the results are presented in Section IV. The experimental analysis is then performed by building a prototype converter which is operable in different soft switching modes (i.e. the ZVS, ZCS and ZVZCS) independently. The experimental results are demonstrated in Section V. It is found that the ZVZCS reduce the loss margin further to improve the efficiency and extends the soft switching range by lowering the dependency on the switch voltage and current. Consequently, the superiority of the ZVZCS over the other soft switching techniques in terms of energy loss reduction capability and extending the soft switching range of operation is proved. Finally, Section VI draws the conclusion.

\section{Analysis of the soft switching modes for energy loss measurement}

The soft switching modes are analyzed to find the gross voltage-current crossover area induced at the turn on instant for each mode and the respective improvement from the hard switching counterpart by simulating the prototype ZVZCS converter [22]. Only the turn on instant is selected for the analysis as the turn off situation can be replicated by replacing simple parameters. To perform the theoretical analysis, the following assumptions are made: a) all the voltage and current transients are considered linearized b) the converter operates in the CCM mode, c) the standard ZVS and ZCS conditions are assumed where the switch voltage and the switch current remains always positive. The specifications are given in Table 1. The PWM switching is described in Section V. It is to be mentioned that the switching transients are typical for a MOSFET. An identical analysis can be performed for an IGBT. In this case, the energy loss would be higher at the turn off because of the tail current. Aside from this, the comparative results will be identical as long as the comparison is made based on energy loss (or the crossover area).

Table 1. Specifications for PSPICE simulation of the prototype converter

\begin{tabular}{|c|c|}
\hline Parameter & Value/Model \\
\hline Mode of operation & Boost \\
\hline PouT & $200 \mathrm{~W}$ \\
\hline$L_{M}$ & $500 \mu \mathrm{H}$ \\
\hline$f_{s}$ & $100 \mathrm{kHz}$ \\
\hline$V_{L}$ & $50 \mathrm{~V}$ \\
\hline$V_{H}$ & $100 \mathrm{~V}$ \\
\hline$L_{r 1}, L_{r 2}$ & $0.47 \mu \mathrm{H}$ \\
\hline$L_{r 3}$ & $0.10 \mu \mathrm{H}$ \\
\hline$C_{r 1}$ & $100 \mu \mathrm{F}$ \\
\hline$C_{L} C_{H}$ & $470 \mu \mathrm{F}$ \\
\hline
\end{tabular}




\subsection{The Hard Switching Mode}

The crossover area that is formed due to the voltage and current rise and fall times (at the switch turn on instant) is shown in Fig. 1. In Fig. 1 (a), the switching waveform pattern for PSPICE simulation is shown to justify the approximation in Fig. 1 (b) for theoretical analysis to be followed. Hence, the crossover area can be approximated by the area of the triangle $\triangle \mathrm{ABC}$

$$
\text { Area of } \triangle \mathrm{ABC}=(0.5)\left(t_{3}-t_{1}\right)(h)
$$

Where, $\left(t_{3}-t_{1}\right)$ is the base and $h$ is the height of the triangle, respectively. Consequently, for switching frequency $f_{s}$, the total energy loss at turn on instant is

$$
E_{H S, t-o n-l o s s}=(0.5)\left(t_{3}-t_{1}\right)(h)\left(f_{s}\right)
$$

It can be assumed that the fall time of the switch voltage $\left(t_{f}\right)$ and the rise time of the switch current $\left(t_{r}\right)$ are equal. Hence, (2) can be rewritten as

$$
E_{H S, t-o n-l o s s}=(0.5)\left(t_{f}\right)(h)\left(f_{s}\right)
$$

Now the switch voltage $v$ can be described as

$$
\frac{v-v_{\max }}{-v_{\max }}=\frac{t-t_{1}}{t_{f}}
$$

where, $t_{1}<t<t_{3}$. The voltage and the current transients intersect at $\mathrm{A}$ located at $t_{2}$ on the $\mathrm{x}$-axis. Hence, the voltage $v$ at $t_{2}$ can be obtained by replacing $t=t_{2}$ in (4),

$$
v_{p}=\left(\frac{t_{2}-t_{1}}{t_{f}}\right)\left(-v_{\max }\right)+v_{\max }
$$

where, $v_{\max }$ is the maximum voltage applied across the switch. Hence, by replicating the concept in (2), the total energy loss at turn on becomes,

$$
\left|E_{H S, t-o n-l o s s}\right|=\left|(0.5)\left(t_{3}-t_{1}\right)\left\{\left(\frac{t_{2}-t_{1}}{t_{f}}\right)\left(-v_{\max }\right)+v_{\max }\right\}\right|\left(f_{s}\right)
$$

Now, from Fig. $1(b)$, it is obvious that $t_{2}-t_{1}=(0.5)\left(t_{3}-t_{1}\right)=0.5 t_{f}$. Hence,

$$
\begin{aligned}
& \left|E_{H S, t-o n-l o s s}\right|=\left|(0.25)\left(t_{f}\right)\left(v_{\max }\right)\right|\left(f_{s}\right) \\
& =\left|\left(0.5 v_{\max }\right)\left(0.5 t_{f}\right)\right|\left(f_{s}\right)
\end{aligned}
$$

where, $f_{s}$ is the switching frequency. Similarly, at turn off, the energy loss is

$$
\left|E_{H S, t-o f f-l o s s}\right|=\left|\left(0.5 v_{\max }\right)\left(0.5 t_{r}\right)\right|\left(f_{s}\right)
$$

where, $t_{r}$ is the voltage rise time.

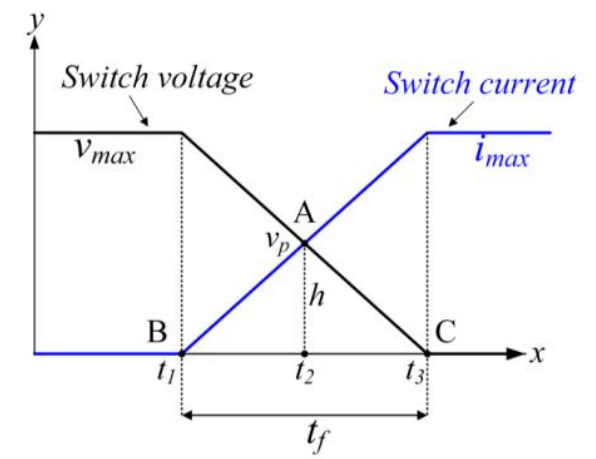

Fig. 1. Linearized hard switching (HS) crossover at turn on instant for theoretical analysis 


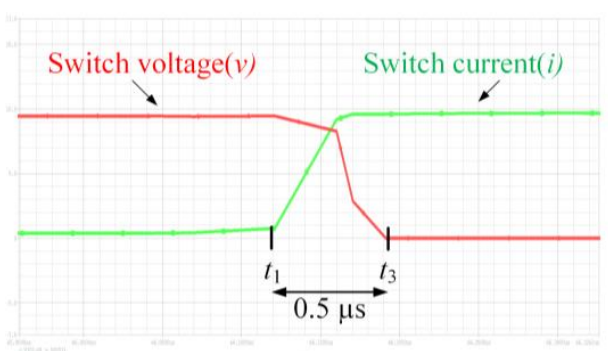

Fig. 2. Simulated waveform at HS turn on instant for the prototype converter

\subsection{The Zero Voltage Switching Mode (ZVS)}

In this mode, the sharp voltage fall at turn on is restricted by emulating zero voltage across the switch. This is done by turning on the body diode of the switch and discharging the passive snubber element. For computation purpose, it is assumed that the voltage transient is linear. The original hard switching curve for $v$ is shown by the broken line. Hence, as obvious from Fig. 2 (b) and justifiable through Fig. 2 (a), the fall time for $v$ is reduced and the voltage-current intersection is shifted left to a new position $\mathrm{D}$ from the hard switching point at $\mathrm{A}$. The new intersection point $\mathrm{D}$ is located in between $t_{2}$ and $t_{1}$ and let it is at $t^{\prime}{ }_{2}$. Consequently, the switch voltage $v$ can be expressed as

$$
\frac{v-v_{\max }}{-v_{\max }}=\frac{t-t_{1}}{t_{2}^{\prime}-t_{1}}=\frac{t-t_{1}}{t_{f, Z V S}}
$$

where, $t_{1}<t<t^{\prime}{ }_{3}$. If voltage is $v^{\prime} p$ at $t^{\prime}{ }_{2}$, then from (9) it can be obtained as

$$
v_{p}^{\prime}=\left(\frac{t_{2}^{\prime}-t_{1}}{t_{3}^{\prime}-t_{1}}\right)\left(-v_{\max }\right)+v_{\max }
$$

Consequently, the energy loss in the ZVS turn on can be derived from (1) as

$$
\begin{aligned}
& \left|E_{\text {ZVS }, t-o n-l o s s}\right|=\left|(0.5)\left(t_{3}^{\prime}-t_{1}\right)\left\{\left(\frac{t_{2}^{\prime}-t_{1}}{t_{3}^{\prime}-t_{1}}\right)\left(-v_{\max }\right)+v_{\max }\right\}\right|\left(f_{s}\right) \\
& =\left|(0.5)\left(t_{f, Z V S}\right)\left\{\left(\frac{t_{2}^{\prime}-t_{1}}{t_{f, Z V S}}\right)\left(-v_{\max }\right)+v_{\max }\right\}\right|\left(f_{s}\right) \\
& =\left|(0.5)\left(-v_{\max }\right)\left\{t_{f, Z V S}-\left(t_{2}^{\prime}-t_{1}\right)\right\}\right|\left(f_{s}\right)
\end{aligned}
$$

where, $t_{f}$, ZVS is the revised switch voltage fall time for the ZVS mode and $t^{\prime}{ }_{3}-t_{1}=t_{f}, \mathrm{ZVS}$. If $t^{\prime}{ }_{2}-t_{1}=t^{\prime}$, then (9) becomes

$$
\left|E_{Z V S, t-o n-l o s s}\right|=\left|(0.5)\left(v_{\max }\right)\left(t_{f, Z V S}-t^{\prime}\right)\right|\left(f_{s}\right)
$$

Now, geometrically to maintain the ZVS mode switching, the following inequality must be true.

$$
\left(t_{f, \text { ZVS }}-t^{\prime}\right)<\left(0.5 t_{f}\right)
$$


The smaller the value of $\left(t_{f}, \mathrm{Zvs}-t^{\prime}\right)$, the better the ZVS execution. Hence, from (7) , (12) and (13), it can be deduced that the energy loss in the ZVS mode is reduced as compared to that in the hard switching counterpart. That is,

$$
\left|E_{Z V S, t-o n-l o s s}\right|<\left|E_{H S, t-o n-l o s s}\right|
$$

For turn off instant, (11) can be rewritten as

$$
\left|E_{\text {ZVS, },-o f f-l o s s}\right|=\left|(0.5)\left(v_{\max }\right)\left(t_{r, Z V S}-t^{\prime}\right)\right|\left(f_{s}\right)
$$

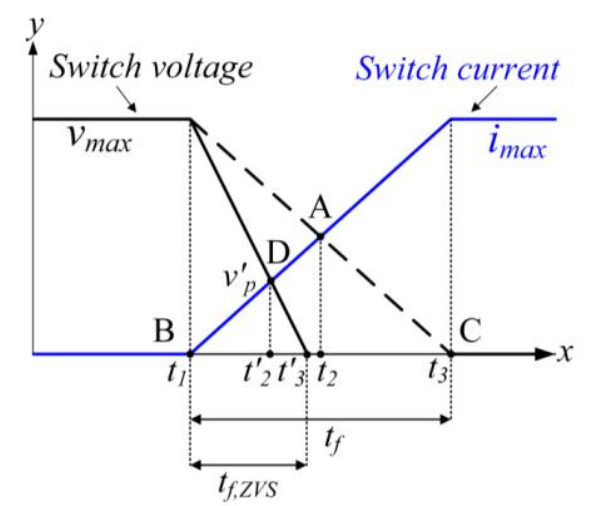

Fig. 3. Linearized zero voltage switching (ZVS) crossover at turn on instant for theoretical analysis

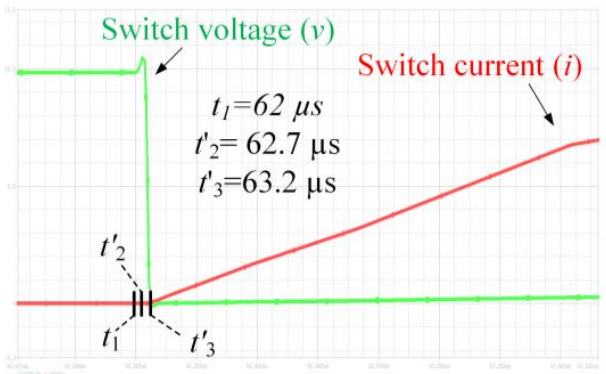

Fig. 4. Simulated waveform at the ZVS mode at turn on instant for the prototype converter

\subsection{The Zero Current Switching Mode}

In contrary to voltage restriction, the ZCS applies current restriction techniques to reduce the crossover area. For this purpose, the current slope is minimized while the voltage transient remains similar as that in hard switching mode. This is shown in Fig. 3. As evident from Fig. 3 (a), the current rise time $\left(t_{r}\right)$ and the voltage fall time $\left(t_{f}\right)$ are different for the ZCS operation. Accordingly, the switch voltage $v$ in Fig. 3 (b) can be derived as

$$
\frac{v-v_{\max }}{-v_{\max }}=\frac{t-t_{1}}{t_{f}}
$$

where, $t_{1}<t<t_{3}$. The voltage and current intersection now shift to the right from A to E located at $t^{\prime \prime}{ }_{2}$ on the $x$-axis. Hence, $v^{\prime \prime} p$ at $t^{\prime \prime}{ }_{2}$ can be defined as

Hence, the energy loss becomes

$$
v_{p}^{\prime \prime}=\left(\frac{t_{2}^{\prime \prime}-t_{1}}{t_{3}-t_{1}}\right)\left(-v_{\text {max }}\right)+v_{\text {max }}
$$




$$
\begin{aligned}
& \left|E_{\text {ZCS,t-on-loss }}\right|=\left|(0.5)\left(t_{3}-t_{1}\right)\left\{\left(\frac{t_{2}^{\prime \prime}-t_{1}}{t_{3}-t_{1}}\right)\left(-v_{\max }\right)+v_{\max }\right\}\right|\left(f_{s}\right) \\
& =\left|(0.5)\left(t_{f}\right)\left(v_{\max }\right)\left(1-\frac{t_{2}^{\prime \prime}-t_{1}}{t_{f}}\right)\right|\left(f_{s}\right) \\
& =\left|(0.5)\left(v_{\max }\right)\left\{t_{f}-\left(t_{2}^{\prime \prime}-t_{1}\right)\right\}\right|\left(f_{s}\right)
\end{aligned}
$$

Here, $t_{3}-t_{1}=t_{t}=t_{f} Z C S$. Now, as $E$ is located far right to the point A in the ZCS operation as obvious from Fig. 3, the following inequality must be true.

$$
\left(t_{2}^{\prime \prime}-t_{1}\right)>\left(0.5 t_{f}\right)
$$

Consequently,

$$
\left\{t_{f}-\left(t_{2}^{\prime \prime}-t_{1}\right)\right\}<\left(0.5 t_{f}\right)
$$

Hence, from (7) and (18), it can be deduced that,

$$
\left|E_{Z C S, t-o n-l o s s}\right|<\left|E_{H S, t-o n-l o s s}\right|
$$

That is, the energy loss is reduced in the ZCS mode as compared to the hard switching counterpart. At turn off (18) becomes,

$$
\left|E_{\text {ZCS, t-on-loss }}\right|=\left|(0.5)\left(v_{\max }\right)\left\{t_{r}-\left(t_{2}^{\prime \prime}-t_{1}\right)\right\}\right|\left(f_{s}\right)
$$

By replacing the parameter values from Fig. 3 (a), the energy loss amounts to

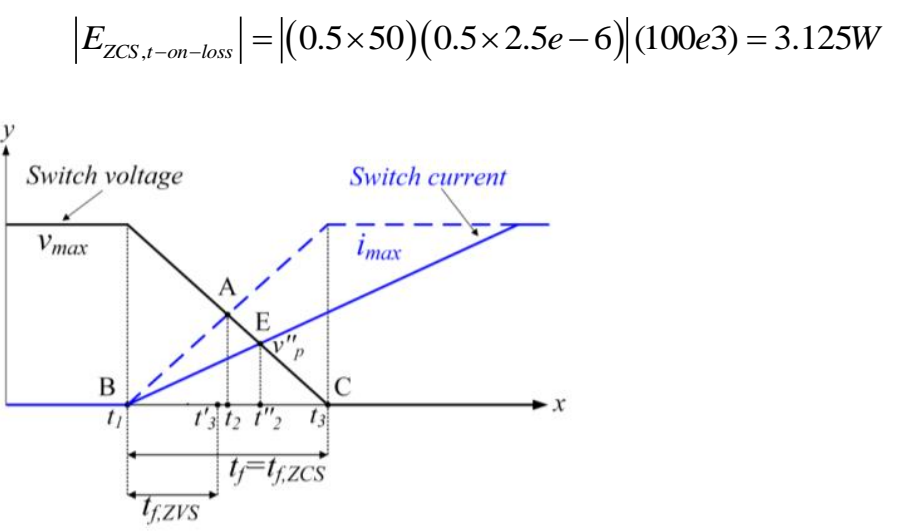

Fig. 5. Linearized zero current switching (ZCS) crossover at turn on instant for theoretical analysis

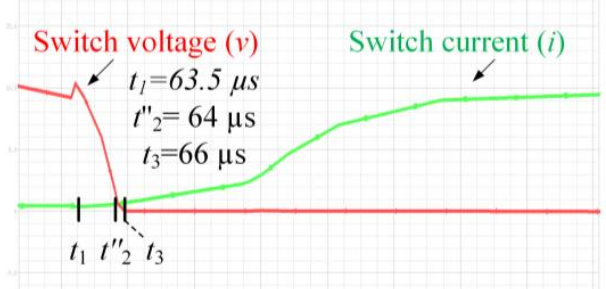

Fig. 6. Simulated waveform at the ZCS mode turn on instant for the prototype converter

\subsection{The True Zero Voltage Zero Current Switching}

In the ZVZCS mode, both the voltage and current transients are altered to minimize the crossover as obvious from Fig. 4 (a). For this case, as obvious from Fig. 4 (b), the voltage and current intersection 
point move to $\mathrm{F}$ to the left of $\mathrm{E}$. This point is located at $t^{\prime \prime \prime}{ }_{2}$ on the $\mathrm{x}$-axis which is different from the ZVS intersection point located at $t^{\prime} 2$. The switch voltage $v$ can be defined as

$$
v=\left(\frac{t-t_{1}}{t_{3}^{\prime}-t_{1}}\right)\left(-v_{\max }\right)+\left(v_{\max }\right)
$$

where, $t_{1}<t<t^{\prime}{ }_{3}$. Now, $v^{\prime \prime \prime}{ }_{p}$ at $t^{\prime \prime \prime}{ }_{2}$ can be defined as

$$
v_{p}^{\prime \prime \prime}=\left(\frac{t_{2}^{\prime \prime \prime}-t_{1}}{t_{3}^{\prime}-t_{1}}\right)\left(-v_{\max }\right)+v_{\max }
$$

Consequently, the energy loss can be defined as

$$
\begin{aligned}
& \left|E_{t-\text { ZVZCS, } t \text {-on-loss }}\right|=\left|(0.5)\left(t_{3}^{\prime}-t_{1}\right)\left\{\left(\frac{t_{2}^{\prime \prime \prime}-t_{1}}{t_{3}^{\prime}-t_{1}}\right)\left(-v_{\max }\right)+v_{\max }\right\}\right|\left(f_{s}\right) \\
& =\mid\left(0.5 v_{\max }\right)\left(t_{f, Z V S}\right)\left[\frac{-\left\{\left(t_{2}^{\prime \prime \prime}-t_{2}^{\prime}\right)+\left(t_{2}^{\prime}-t_{1}\right)\right\}}{t_{f, Z V S}}+1\right]\left(f_{s}\right) \\
& =\left|\left(0.5 v_{\max }\right)\left(t_{f, Z V S}\right)\left[\frac{-\left\{\left(t_{2}^{\prime \prime \prime}-t_{2}^{\prime}\right)+t^{\prime}\right\}}{t_{f, Z V S}}+1\right]\right|\left(f_{s}\right) \\
& =\left|\left(0.5 v_{\max }\right)\left\{t_{f, Z V S}-\left(t^{\prime}+x\right)\right\}\right|\left(f_{s}\right)
\end{aligned}
$$

Here, $t^{\prime}{ }_{3}-t_{1}=t_{f, Z V Z C S}=t_{f, Z V S}$ and $t^{\prime}{ }_{2}-t_{1}=\mathrm{t}^{\prime}$. Moreover, $x$ is defined as

$$
x=t_{2}^{\prime \prime \prime}-t_{2}^{\prime}
$$

As $\mathrm{F}$ is located at the right of $\mathrm{D}, x$ must be positive. Hence, it is obvious from (22) and (25) that the energy loss in the ZVZCS mode is further truncated as compared to the ZVS or ZCS. For the turn off instant, (26) can be rewritten as

$$
\left|E_{t-\text { ZVZCS, } t \text {-off-loss }}\right|=\left|\left(0.5 v_{\max }\right)\left\{t_{f, Z V S}-\left(t^{\prime}+x\right)\right\}\right|\left(f_{s}\right)
$$

Hence, from (7), (11), (18) and (25), it becomes obvious that the ZVZCS mode switching is more efficient in reducing the energy loss at the turn on point than the ZVS or the ZCS. More specifically, as compared to the ZVS, the ZVZCS reduces the loss in percentage by

$$
\begin{aligned}
& E_{t-o n-l o s s-\text { reduction }}=\frac{\left|E_{Z V S, t-o n-l o s s}\right|-\left|E_{Z V Z C S, t-o n-l o s s}\right|}{\left|E_{Z V S, t-o n-l o s s}\right|} \times 100 \\
& =\frac{t_{2}^{\prime \prime \prime}}{t_{f, Z V S}+t_{1}} \times 100
\end{aligned}
$$

Roughly the net loss reduction in percentage at the turn on and turn off should be,

$$
E_{\text {total-loss-reduction }}=\frac{1.5 t_{2}^{\prime \prime \prime}}{t_{f, Z V S}+t_{1}} \times 100
$$

As compared to the ZCS, the loss reduction can be defined as

$$
\begin{aligned}
& E_{t-o n-l o s s-r e d u c t i o n}=\frac{\left|E_{Z C S, t-o n-l o s s}\right|-\left|E_{Z V Z C S, t-o n-l o s s}\right|}{\left|E_{Z C S, t-o n-l o s s}\right|} \times 100 \\
& =\frac{t_{f, Z V S}}{t_{2}^{\prime \prime}-t_{1}} \times 100
\end{aligned}
$$

Again, the net loss reduction as compared to the ZCS in percentage should be,

$$
E_{\text {total-loss-reduction }}=\frac{1.5 t_{f, Z V S}{ }^{\prime \prime}}{t_{2}^{\prime \prime}-t_{1}} \times 100
$$


By replacing the parameter values from Fig. 8, the energy loss in ZVZCS mode amounts to

$$
\left|E_{\text {ZVZCS,t-on-loss }}\right|=|(0.5 \times 50)(0.5 \times 0.7 e-6)|(100 e 3)=875 \mathrm{~mW}
$$

Hence, it can be concluded that the ZVZCS is capable of reducing the energy loss at the switch transition points as compared to that induced in the HS, ZVS or the ZCS mode.

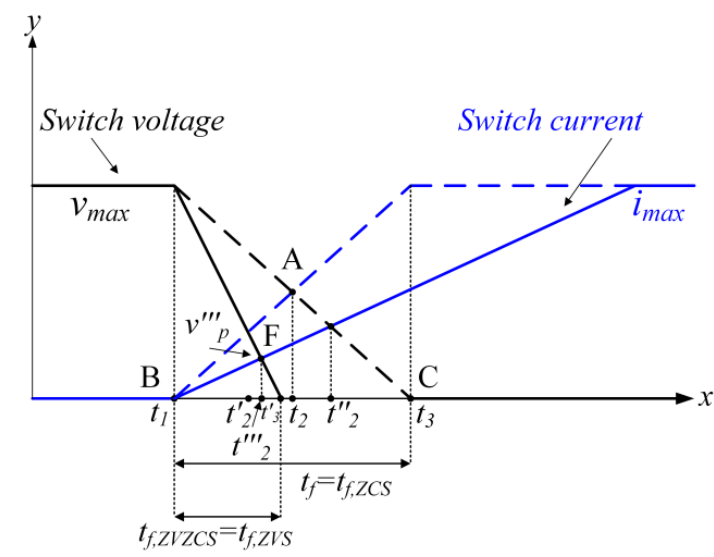

Fig. 7. Linearized zero current switching (ZCS) crossover at turn on instant for theoretical analysis

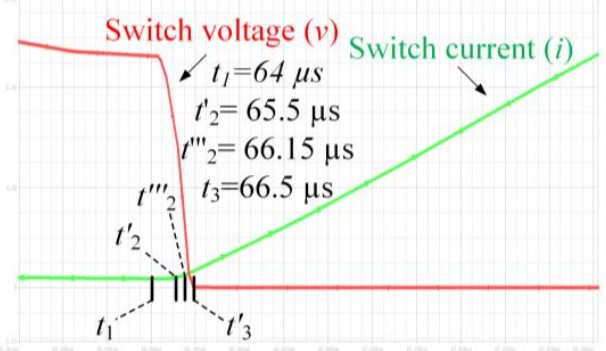

Fig. 8. Simulated waveform at the ZVZCS mode turn on instant for the prototype converter

\section{Analysis for the estimation of the soft switching range}

\subsection{The Zero Voltage Switching (ZVS)}

In the ZVS, the turn on loss is defined in terms of input voltage as

$$
\left|E_{\text {ZVS }, t-o n-l o s s}\right|=\left|(0.5)\left(v_{\max }\right)\left(t_{f, Z V S}-t^{\prime}\right)\right|\left(f_{s}\right)
$$

Or in terms of switch current, it can be rewritten as

$$
\left|E_{\text {ZVS, } t-o n-l o s s}\right| \approx\left|(0.5)(0.25)\left(i_{\max }\right)\left(t_{f, Z V S}\right)\right|\left(f_{s}\right)
$$

It can be observed that the ZVS turn on loss largely depends on the maximum applied switch voltage $v_{\max }$ which is the input voltage for a forward mode converter. This dependency can be reduced if switching frequency $\left(f_{\mathrm{s}}\right)$ is decreased. However, it is not an effective solution to reducing the switching frequency would increase the size of the passive components, while, the term $\left(t, z v s-t^{\prime}\right)$ is constant. On the other hand, the dependency on the switch current is much weaker as obvious from (32). Hence, this large dependency on the switch voltage makes the ZVS operation largely vulnerable to the input voltage and duty cycle ratio. Subsequently, the ZVS operation is difficult to maintain for the wide operating window. 


\subsection{The Zero Current Switching (ZCS)}

In the ZCS, the energy loss in terms of maximum switch voltage $\left(v_{\max }\right)$ and current $\left(i_{\max }\right)$ are described as

$$
\left|E_{\text {ZCS, },-o n-l o s s}\right|=\left|(0.5)\left(v_{\max }\right)\left\{t_{f}-\left(t_{2}^{\prime \prime}-t_{1}\right)\right\}\right|\left(f_{s}\right)
$$

and

$$
\left|E_{\text {ZCS,t-on-loss }}\right| \approx\left|(0.5)\left(i_{\max }\right)\left(t_{f}\right)\left(\frac{t_{2}^{\prime \prime}}{t_{4}}\right)\right|\left(f_{s}\right)
$$

In (34), as obvious from Fig. 3,

$$
t_{f} \approx\left(t_{2}^{\prime \prime}-t_{1}\right)
$$

Hence, the maximum switch voltage $\left(v_{\max }\right)$ has minimal effect on the ZCS operation. On the contrary, the ZCS operation is largely affected by $i_{\max }$ as can be seen in (35). To reduce this effect, $f_{\mathrm{s}}$ has to be minimized as the term $\left(t_{2}^{\prime \prime \prime} / t_{4}\right)$ is constant. However, as mentioned earlier, it is not an effective solution as the size of the passive components can increase substantially. The dependency on the switch current makes the ZCS operation vulnerable to the converter loading conditions. Consequently, for wide load variation, the ZCS is difficult to achieve. In other words, the soft switching range of operation is affected.

\subsection{The True Zero Voltage Zero Current Switching}

In this mode, the energy loss terms are

$$
\begin{aligned}
& \left|E_{t-\text { ZVZCS, }, \text {-on-loss }}\right|=\left|\left(0.5 v_{\max }\right)\left\{t_{f, Z V S}-\left(t^{\prime}+x\right)\right\}\right|\left(f_{s}\right) \\
& =\left|\left(0.5 v_{\max }\right)\left\{t_{f, Z V S}-\left(t_{2}^{\prime \prime \prime}-t_{1}\right)\right\}\right|\left(f_{s}\right)
\end{aligned}
$$

or

$$
\left|E_{t-Z V Z C S, t-o n-l o s s}\right|=\left|\left(0.5 i_{\max }\right)\left(t_{f, Z V S}\right)\left(\frac{t_{2}^{\prime \prime \prime}}{t_{4}}\right)\right|\left(f_{s}\right)
$$

It can be deduced from Fig. 4 that

$$
t_{f, Z v S} \approx\left(t_{2}^{\prime \prime \prime}-t_{1}\right)
$$

Hence, it is obvious from (37) that the maximum switch voltage has minimal effect on the true ZVZCS. Similarly, it can be observed from Fig. 4 that

$$
t_{2}^{\prime \prime \prime}=t_{4}
$$

Subsequently, as obvious from (38), the dependency of the ZVZCS operation on the switch current is negligible. Hence, the ZVZCS is not largely affected by the input voltage and loading conditions. In return, it becomes capable of providing wider soft switching range by remaining operational irrespective of the input voltage and load current conditions.

\section{Simulation Results for comparative analysis}

To prove the theoretical statement, a PSPICE simulation is performed for selected topologies from the recent literature. The converters are simulated in the boost mode and the following specifications are maintained:

Table 2. Common specifications

\begin{tabular}{|l|l|}
\hline Parameter & Value/Model \\
\hline Mode of operation & Boost \\
\hline PouT & $200 \mathrm{~W}$ \\
\hline
\end{tabular}




\begin{tabular}{|l|l|}
\hline$L M$ & $500 \mu \mathrm{H}$ \\
\hline All switches & MOSFET IRF150 \\
\hline
\end{tabular}

Furthermore, the converters are intentionally operated at a low power level (i.e. $200 \mathrm{~W}$ ) for better visualization of the switching losses. The main switches of the converters are taken into consideration to measure the incurred turn on and turn off losses while the converters are operated either in a) the ZVS mode or b) the ZCS mode or c) the ZVZCS mode. The measurement is performed in different states (State A to State F) of the circuit. Each state denotes a unique combination of switching frequency $\left(f_{s}\right)$, the input voltage $\left(V_{L}\right)$ and the load current. The variation of the operational states makes the results unbiased to the operating conditions of the converter. Furthermore, the measured turn on and turn off losses for different soft switching conditions are averaged out to achieve more accurate results. The simulation results are demonstrated in Table 3 below.

Table 3. Turn on and turn off loss in the main switch

\begin{tabular}{|c|c|c|c|c|}
\hline \multicolumn{5}{|c|}{ State A: $f_{S}=50 \mathrm{kHz}$, Pout $=200 \mathrm{~W}, V_{L}=50 \mathrm{~V}$} \\
\hline \multirow{2}{*}{$\begin{array}{l}\text { Refs. for } \\
\text { Simulated } \\
\text { topology }\end{array}$} & \multicolumn{2}{|c|}{ Soft switching mode } & \multicolumn{2}{|c|}{ Loss $(\mathrm{mW})$} \\
\hline & Turn on & Turn off & Turn on & Turn off \\
\hline$[\underline{4}]$ & ZVS & ZVS & 1200 & 500 \\
\hline [6] & ZVS & ZVS & 1400 & 650 \\
\hline [3] & ZVS & ZVS & 1150 & 520 \\
\hline [1] & ZCS & ZCS & 1480 & 780 \\
\hline [5] & ZCS & ZCS & 1450 & 745 \\
\hline$[\underline{13}]$ & ZCS & ZCS & 1440 & 745 \\
\hline [2] & ZCS & ZVS & 1390 & 540 \\
\hline$[\underline{23}]$ & ZVZCS & ZVZCS & 950 & 520 \\
\hline [24] & ZVZCS & ZVZCS & 850 & 440 \\
\hline$[\underline{25}]$ & ZVZCS & ZVZCS & 820 & 410 \\
\hline \multicolumn{5}{|c|}{ State B: $f_{S}=50 \mathrm{kHz}$, PouT $=200 \mathrm{~W}, V_{L}=100 \mathrm{~V}$} \\
\hline \multirow{2}{*}{$\begin{array}{l}\text { Simulated } \\
\text { topology }\end{array}$} & \multicolumn{2}{|c|}{ Soft switching mode } & \multicolumn{2}{|c|}{ Loss $(\mathrm{mW})$} \\
\hline & Turn on & Turn off & Turn on & Turn off \\
\hline$[\underline{4}]$ & ZVS & ZVS & 1350 & 550 \\
\hline [] & ZVS & ZVS & 1480 & 690 \\
\hline [3] & ZVS & ZVS & 1330 & 560 \\
\hline [1] & ZCS & ZCS & 1405 & 750 \\
\hline [] & ZCS & ZCS & 1380 & 710 \\
\hline$[\underline{13}]$ & ZCS & ZCS & 1390 & 725 \\
\hline [2] & ZCS & ZVS & 1340 & 630 \\
\hline [23] & ZVZCS & ZVZCS & 1080 & 550 \\
\hline [24] & ZVZCS & ZVZCS & 950 & 480 \\
\hline [25] & ZVZCS & ZVZCS & 875 & 355 \\
\hline \multicolumn{5}{|c|}{ State C: $f_{S}=50 \mathrm{kHz}$, PouT $=200 \mathrm{~W}, V_{L}=150 \mathrm{~V}$} \\
\hline \multirow{2}{*}{$\begin{array}{c}\text { Simulated } \\
\text { topology }\end{array}$} & \multicolumn{2}{|c|}{ Soft switching mode } & \multicolumn{2}{|c|}{ Loss $(\mathrm{mW})$} \\
\hline & Turn on & Turn off & Turn on & Turn off \\
\hline$[\underline{4}]$ & ZVS & ZVS & 1470 & 620 \\
\hline [] & ZVS & ZVS & 1540 & 730 \\
\hline$[\underline{3}]$ & ZVS & ZVS & 1420 & 580 \\
\hline [1] & ZCS & ZCS & 1380 & 720 \\
\hline [] $]$ & ZCS & ZCS & 1305 & 690 \\
\hline$[\underline{13}]$ & ZCS & ZCS & 1355 & 705 \\
\hline [2] & ZCS & ZVS & 1515 & 695 \\
\hline [23] & ZVZCS & ZVZCS & 920 & 515 \\
\hline
\end{tabular}




\begin{tabular}{|c|c|c|c|c|}
\hline [24] & ZVZCS & ZVZCS & 880 & 440 \\
\hline [25] & ZVZCS & ZVZCS & 785 & 425 \\
\hline \multicolumn{5}{|c|}{ State D: $f_{S}=100 \mathrm{kHz}$, PouT $=200 \mathrm{~W}, V_{L}=50 \mathrm{~V}$} \\
\hline \multirow{2}{*}{$\begin{array}{c}\text { Simulated } \\
\text { topology }\end{array}$} & \multicolumn{2}{|c|}{ Soft switching mode } & \multicolumn{2}{|c|}{ Loss $(\mathrm{mW})$} \\
\hline & Turn on & Turn off & Turn on & Turn off \\
\hline [] & ZVS & ZVS & 1750 & 760 \\
\hline [] & ZVS & ZVS & 1820 & 840 \\
\hline [3] & ZVS & ZVS & 1680 & 740 \\
\hline [1] & ZCS & ZCS & 1850 & 950 \\
\hline [5] & ZCS & ZCS & 1810 & 870 \\
\hline [13] & ZCS & ZCS & 1830 & 840 \\
\hline$[2]$ & ZCS & ZVS & 1840 & 805 \\
\hline [23] & ZVZCS & ZVZCS & 1345 & 615 \\
\hline [24] & ZVZCS & ZVZCS & 1285 & 550 \\
\hline [25] & ZVZCS & ZVZCS & 1270 & 500 \\
\hline \multicolumn{5}{|c|}{ State $\mathrm{E}: f_{S}=100 \mathrm{kHz}, P_{\text {OUT }}=200 \mathrm{~W}, V_{L}=100 \mathrm{~V}$} \\
\hline \multirow{2}{*}{$\begin{array}{c}\text { Simulated } \\
\text { topology }\end{array}$} & \multicolumn{2}{|c|}{ Soft switching mode } & \multicolumn{2}{|c|}{ Loss $(\mathrm{mW})$} \\
\hline & Turn on & Turn off & Turn on & Turn off \\
\hline$[\underline{4}]$ & ZVS & ZVS & 1820 & 810 \\
\hline [] & ZVS & ZVS & 1880 & 870 \\
\hline [3] & ZVS & ZVS & 1780 & 750 \\
\hline [1] & ZCS & ZCS & 1780 & 920 \\
\hline [5] & ZCS & ZCS & 1785 & 840 \\
\hline [13] & ZCS & ZCS & 1790 & 820 \\
\hline [2] & ZCS & ZVS & 1785 & 850 \\
\hline [23] & ZVZCS & ZVZCS & 1265 & 675 \\
\hline [24] & ZVZCS & ZVZCS & 1200 & 590 \\
\hline [25] & ZVZCS & ZVZCS & 1165 & 525 \\
\hline \multicolumn{5}{|c|}{ State $\mathrm{F}: f_{S}=100 \mathrm{kHz}$, PouT $=200 \mathrm{~W}, V_{L}=150 \mathrm{~V}$} \\
\hline \multirow{2}{*}{$\begin{array}{l}\text { Simulated } \\
\text { topology }\end{array}$} & \multicolumn{2}{|c|}{ Soft switching mode } & \multicolumn{2}{|c|}{ Loss $(\mathrm{mW})$} \\
\hline & Turn on & Turn off & Turn on & Turn off \\
\hline$[\underline{4}]$ & ZVS & ZVS & 1860 & 830 \\
\hline [] & ZVS & ZVS & 1950 & 920 \\
\hline [3] & ZVS & ZVS & 1805 & 780 \\
\hline [1] & ZCS & ZCS & 1745 & 880 \\
\hline [5] & ZCS & ZCS & 1735 & 800 \\
\hline [13] & ZCS & ZCS & 1755 & 785 \\
\hline [2] & ZCS & ZVS & 1730 & 865 \\
\hline [23] & ZVZCS & ZVZCS & 1395 & 685 \\
\hline [24] & ZVZCS & ZVZCS & 1320 & 620 \\
\hline [25] & ZVZCS & ZVZCS & 1285 & 555 \\
\hline
\end{tabular}

To provide a better visual understanding, the average turn on and turn off losses induced in the ZVS, the ZCS or in the ZVZCS mode are plotted in Fig. 5 and 6 respectively at different operational states. As can be seen, the average turn on loss from State A to State F increases from $1200 \mathrm{~mW}$ to $1800 \mathrm{~mW}$, while the turn off loss increase from $550 \mathrm{~mW}$ at State A to $850 \mathrm{~mW}$ at State F. For the ZCS, the turn on loss at State A is $1400 \mathrm{~mW}$ which becomes $1700 \mathrm{~mW}$ at State F, while it increases from $700 \mathrm{~mW}$ to 850 $\mathrm{mW}$ at turn off. In contrary, in the ZVZCS mode, the turn on loss is $880 \mathrm{~mW}$ at State A which increases to $1300 \mathrm{~mW}$ at State F. Moreover, the turn off loss is $450 \mathrm{~mW}$ at State A to $600 \mathrm{~mW}$ at State F. On average, the loss at the turn on and turn off for the ZVZCS are reduced by $26 \%$ and $20 \%$ respectively, as can be deduced from Figs. 5 and 6 respectively. 


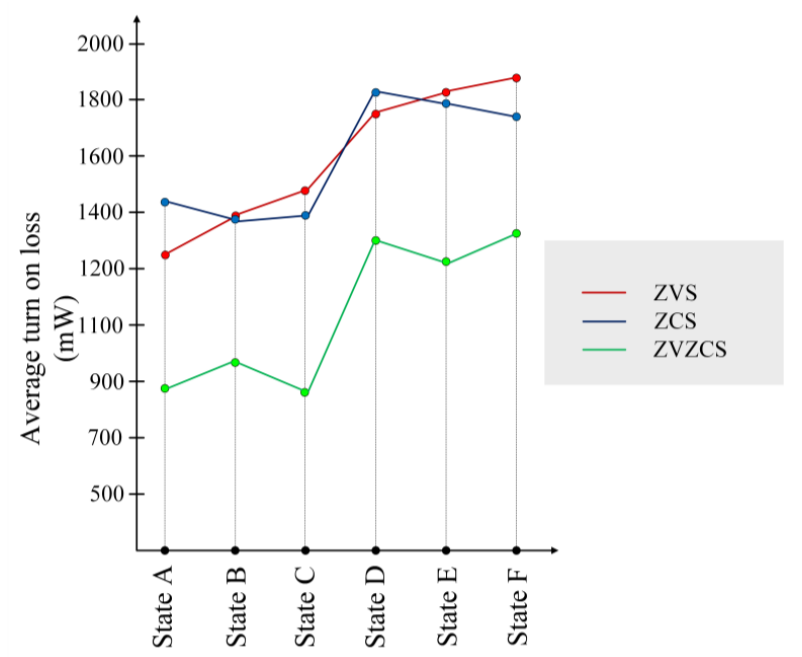

Fig. 5. Average turn on loss in the main switch

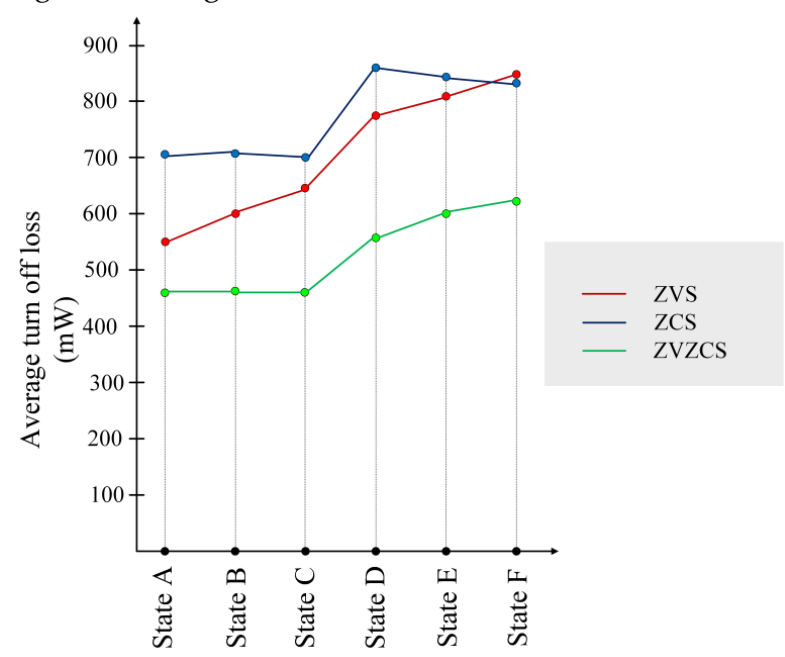

Fig. 6. Average turn off loss in the main switch

To provide an insight into the soft switching range of operation 1) the average turn on and turn off losses out of all the six states and 2) the cumulated standard deviations from the average values are calculated. The results are shown in Table 4 below. As can be observed, the ZVZCS incurs the lowest turn on and turn off losses on average. Besides, the standard deviation (SD) shows that the deviation from the average is fairly lower for the ZVZCS mode as compared to others. This signifies stable low loss profile throughout all six states and proves the superiority of the ZVZCS soft switching performance in the whole operating range.

Table 4. Average turn on and turn off losses out of all six states

\begin{tabular}{|c|c|r|r|r|}
\hline \multirow{2}{*}{ Soft switching mode } & \multicolumn{2}{|c|}{ Average loss $(\mathrm{mW})$} & \multicolumn{2}{c|}{ Standard Deviation } \\
\cline { 2 - 5 } & Turn on & Turn off & Turn on & \multicolumn{1}{c|}{ Turn off } \\
\hline ZVS & 1570 & 690 & 241.98 & 109.45 \\
\hline ZCS & 1585 & 770 & 193.83 & 76.46 \\
\hline ZVZCS & 1080 & 520 & 197.22 & 68.58 \\
\hline
\end{tabular}

\section{Experimental verification}

To verify the theoretical claim, an experimental test is performed. A prototype ZVZCS converter [22] is built to evaluate the switching losses under various soft switching conditions. The simulation waveforms for the prototype converter are demonstrated in Figs. (1) to (4) for different switching 
states. In this section, the experimental test procedure is discussed. The description of the converter operational modes, intervals and results are to be followed in the rest of this section.

\subsection{Converter Topology and PWM Switching}

The converter (as shown in Fig. 7) consists of the main switches $S_{1}$ and $S_{2}$, the auxiliary switches $\mathrm{Sr}_{1}$ and $\mathrm{Sr}_{2}$, the main inductor $L m_{1}$, the auxiliary inductors $L r_{1}$ and $L r_{2}$ and the auxiliary capacitor $C r_{1}$. It is bidirectional and operable in the ZVS, the ZCS and the ZVZCS mode separately. For the experimental verification, the converter is tested in the boost mode only and the turn on and turns off losses are calculated for the main switch $S_{1}$. For this purpose, the circuit is operated in four different stages, namely

Stage 1: the ZVZCS mode

Stage 2: the ZVS mode

Stage 3: the ZCS mode and

Stage 4: the hard switching (HS) mode

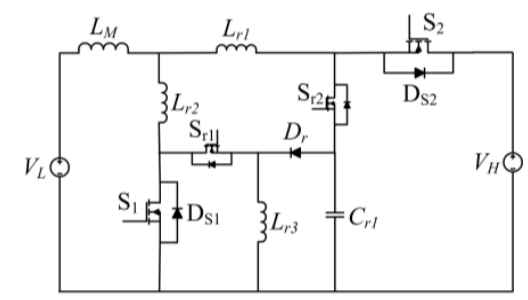

Fig. 7. The schematic of the ZVZCS converter under test [르]

In Stage 1, the turn on and turn off of $S_{1}$ is conducted in the ZVZCS mode. To achieve this, both the auxiliary switches ( $\mathrm{Sr}_{1}$ and $\mathrm{Sr}_{2}$ ) are turned on as shown in Fig. 8 (a). This leads to the near zero switching loss at the transitions. In Stage 2, $\mathrm{Sr}_{1}$ is turned on and $\mathrm{Sr}_{2}$ is turned off as shown in Fig. 8 (b). Consequently, $\mathrm{S}_{1}$ is operated in the ZVS mode. The sharp voltage rise across the switch $\mathrm{S}_{1}$ is controlled by the ZVS mode switching by turning on the respective body diode. In Stage 3, to achieve the ZCS at $S_{1}$, the $S_{1}$ is turned off and $S_{2}$ is turned on as in Fig. 8 (c). This forces the body diode of $S_{1}$ to remain turned off. Simultaneously, the $\mathrm{Lr}_{2}$ and the capacitor $\mathrm{Cr} r_{1}$ realize the ZCS operation in $\mathrm{S}_{1}$. For this purpose, $L_{r 1}$ and $L_{r 2}$ control the sharp rise of current through $S_{1}$. Finally in Stage 4 , for the hard switching stage, both the auxiliary switches (i.e. $\mathrm{Sr}_{1}$ and $\mathrm{Sr}_{2}$ ) are turned off as shown in Fig. 8 (d). To give a general idea on the operation of the circuit, the operational intervals are shortly described next.

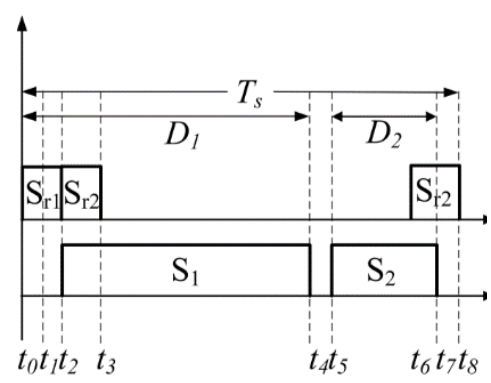

(a)

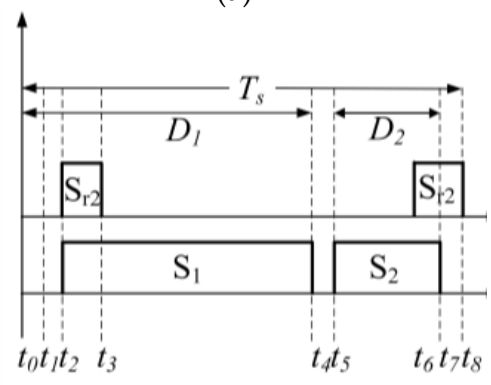

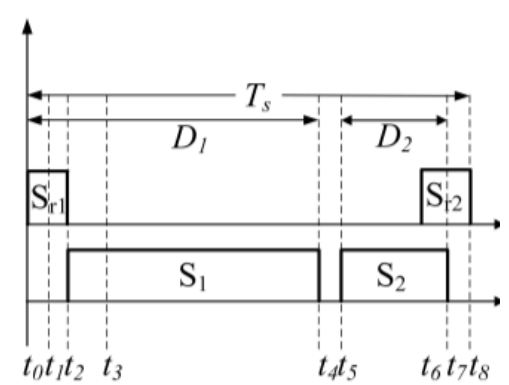

(b)

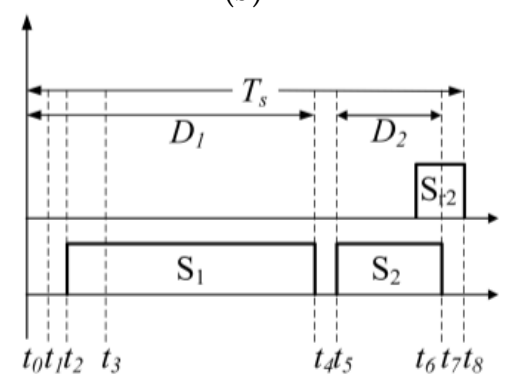


(c)

(d)

Fig. 8. The PWM switching in (a) Stage 1 (b) Stage 2 (c) Stage 3 (d) Stage 4

\subsection{Converter Operational Intervals}

The operational intervals are important to understanding the basic operation of the circuit. Hence, the operational intervals are described in short which should be sufficient to understand the soft switching operation.

\section{a) Interval 1 [t1-to, Stage 1+ Stage 2]:}

At to, the auxiliary switch $\mathrm{S}_{\mathrm{r} 1}$ is turned on in the ZVS mode. The current starts to flow through $\mathrm{S}_{\mathrm{r} 1}$ and subsequently charges the resonant inductor $L_{r 3}$. The capacitor $C_{r 1}$ turns on the diode $D_{r}$ and discharges to the $L_{r 3}$ through the diode. Throughout this interval, the inductor current $i_{L M}$ remains constant and discharges to the output. The time interval $t_{10}$ is determined as

$$
t_{10} \geq 5 \tau_{S}=5\left(\frac{L_{r_{2}}+L_{r_{3}}}{R_{L r_{2}}+R_{L r_{3}}}\right)=5\left(\frac{L_{T}}{R_{T}}\right)
$$

b) Interval 2 [t2-t1, Stage 1+ Stage 2]:

At $t_{1}$, the body diode of $S_{1}$ is turned on and $L_{r 3}$ starts to discharge through it. This, in return, enables $S_{1}$ to be turned on in the ZVS mode at $t_{2}$. At $t_{2}$, the current through the switch $S_{r 1}$ reaches zero and $S_{r 1}$ is turned off in ZCS mode. To allow $L_{r 3}$ to discharge completely, $t_{21}$ has to be selected as

$$
t_{21} \geq 3 \tau_{S}=3\left(\frac{L_{r_{2}}+L_{r_{3}}}{R_{L r_{2}}+R_{L r_{3}}}\right)=3\left(\frac{L_{T}}{R_{T}}\right)
$$

Combining (1) and (2), the following relationship is obtained.

$$
t_{20} \geq 8 \tau_{S}
$$

Thus, as long as the lower limit restrictions in (1) and (2) are satisfied, the ZVS condition is achievable. However, to avoid unnecessary losses in the auxiliary components and the body diode of the main switch, the delay should be kept equal to or lower than twice the minimum limit. Hence, the functional range of $t_{20}$ should be

$$
16 \tau_{S} \geq t_{20} \geq 8 \tau_{S}
$$

c) Interval 3 [t3-t2, Stage 1+ Stage 3]:

At $t_{2}$, the switch $S_{1}$ is turned on in the ZVZCS mode. To achieve this purpose, the inductor $L_{r 2}$ in series with $S_{1}$, restricts the sharp rise of current through the switch. In general, as the value of the inductor $L_{r 2}$ increases, the slope $d i / d t$ decreases as obvious from (5). However, excessively large $L_{r 3}$ would affect the ZVS transition of $S_{1}$. At $t_{3}$, $S_{r 2}$ is turned on for a very short period. Consequently, $C_{r 1}$ is charged by the reverse recovery current $i_{r}$. To this purpose, $C_{r 1}$ is designed to be able to accommodate the reverse recovery charge $Q_{r r}$.

$$
\frac{d i_{L r_{2}}}{d t}=\frac{V_{L}}{L_{r_{2}}}
$$

d) Interval $4\left[\mathrm{t}_{4}-\mathrm{t}_{3}\right.$, Stage 1-4]:

Throughout this interval, the inductor current $i_{L M}$ continues to increase. At $t_{4}, S_{1}$ is turned off in the ZVZCS mode. 


$$
\frac{d i_{L_{M}}}{d t}=\frac{V_{L}}{L_{M}}
$$

e) Interval 5 [ $\mathrm{t}_{5}-\mathrm{t}_{4}$, Stage $\left.1-4\right]$ :

This interval is kept short enough to avoid any unnecessary current stress on the power switches and simultaneously to avoid the short circuit condition while both $S_{1}$ and $S_{2}$ are switched on.

f) Interval 6 [t 6 - $\mathrm{t}_{5}$, Stage 1-4]:

At $t_{6}$, switch $S_{2}$ is turned on in the ZVZCS mode. Consequently, the inductor LM starts to discharge through $S_{2}$. The inductor current $\left(i_{L M}\right)$ decreases as

$$
\frac{d i_{L_{M}}}{d t}=\frac{V_{L}-V_{H}}{L_{M}}
$$

g) Interval 7 [ts-t7, Stage 1-4]:

Throughout this interval, the body diode of $S_{2}$ remains open. Thus, the inductor $L_{M}$ continues to discharge through the body diode of the switch $S_{2}$. At the end of this interval, $S_{r 2}$ is turned off in the ZVS mode. iLM decreases as

$$
\frac{d i_{L_{M}}}{d t}=\frac{V_{L}-V_{C_{r_{1}}}}{L_{M}}
$$

\subsection{Experimental Setup}

The prototype circuit is shown in Fig. 9. The circuit is built according to the following specifications:

Table 5. Circuit parameter values

\begin{tabular}{|l|l|}
\hline Parameter & Value \\
\hline$P_{O}$ & $150 \mathrm{~W}$ \\
\hline$L_{M}$ & $1000 \mu \mathrm{H}$ \\
\hline$f_{s}$ & $100 \mathrm{kHz}$ \\
\hline$V_{L}$ & $50 \mathrm{~V}$ \\
\hline$V_{H}$ & $120 \mathrm{~V}$ \\
\hline$L_{r 1} L_{r 2}$ & $0.47 \mu \mathrm{H}$ \\
\hline$L_{r 3}$ & $0.10 \mu \mathrm{H}$ \\
\hline$C_{r 1}$ & $100 \mu \mathrm{F}$ \\
\hline$C_{L}, C_{H}$ & $470 \mu \mathrm{F}$ \\
\hline
\end{tabular}

The TMS320F2812 DSP is used to generate PWM pulses. The DSP has 12 PWM channels and $150 \mathrm{MHz}$ of clock frequency. Both the high and low voltage side power transistors are implemented with IPW50R190CE $\left(550 \mathrm{~V}, 63 \mathrm{~A}, R_{d s}(\right.$ on) $=190 \mathrm{~m} \Omega)$ MOSFET. The low power auxiliary switches are implemented with FDP15N40 (400 V, $15 \mathrm{~A}, R_{d s}($ on) $=300 \mathrm{~m} \Omega)$ MOSFET. The ITECH IT8816B DC electronic load is used for testing purposes. The converter is operated at 0.5 duty cycle ratio. 


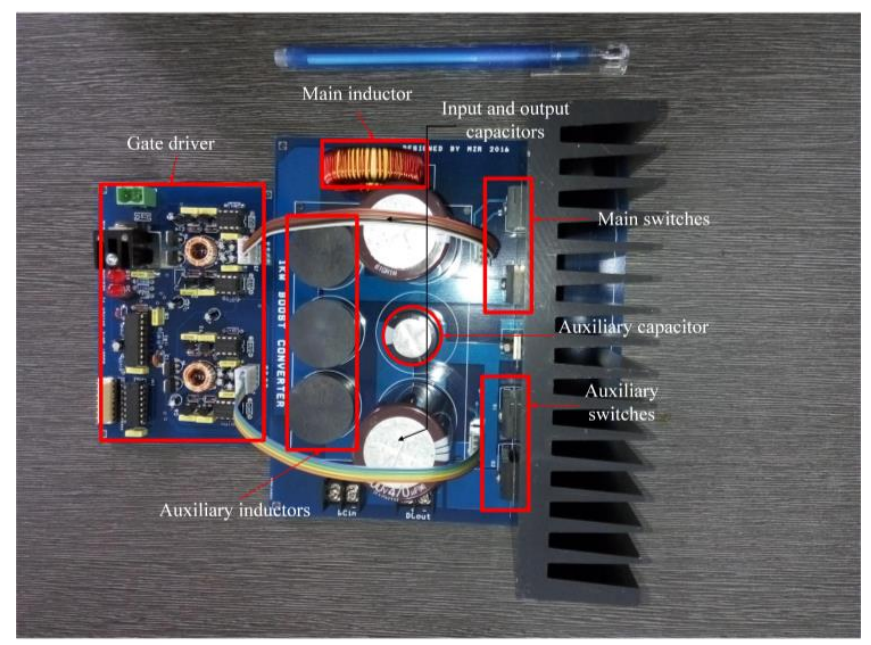

Figure. 9. Experimental prototype circuit

\subsection{Results and Discussion}

For all cases, the switching losses are measured in switch $S_{1}$. In Fig. 10, the voltage and current waveforms of $S_{1}$ are shown for different switching conditions. The measured losses are given in Table 6. It can be observed from Table 4 that the ZVS and ZCS provide improve the switching states and reduce the losses as compared to the hard switching condition by more than $30 \%$. However, the improvement induced by the ZVZCS operation from the HS counterpart is more than $80 \%$ which surpasses other soft switching conditions. Thus, the efficiency is largely improved.

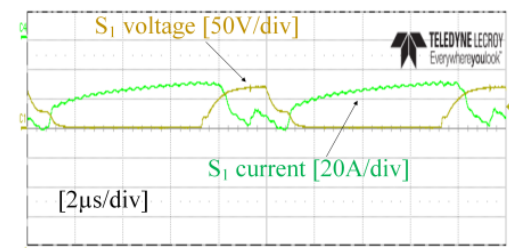

(a)

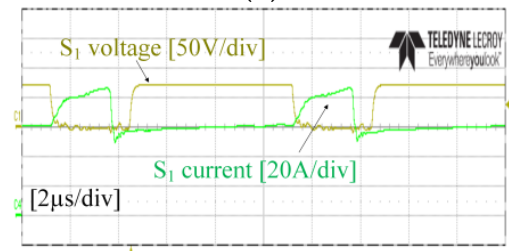

(c)

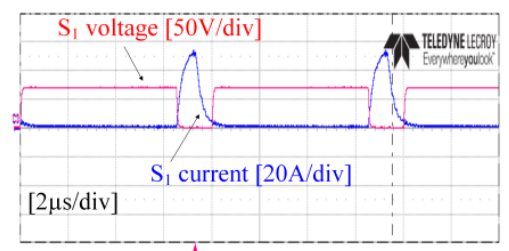

(b)

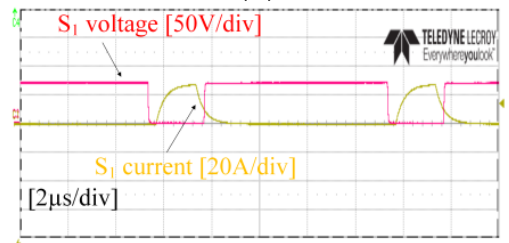

(d)

Figure. 10. Voltage and current waveforms of $\mathrm{S}_{1}$ at the (a) HS (b) ZVS (c) ZCS (d) true ZVZCS conditions

Table 6. Loss in the switch $S_{1}$

\begin{tabular}{|c|c|c|}
\hline $\begin{array}{l}\text { Switching } \\
\text { mode }\end{array}$ & $\begin{array}{c}\text { Turn on loss in } \mathrm{S}_{1} \\
(\mathrm{~mW})\end{array}$ & $\begin{array}{c}\text { Turn off loss in } \mathrm{S}_{1} \\
(\mathrm{~mW})\end{array}$ \\
\hline Hard & 1600 & 1850 \\
\hline ZVS & 620 & 400 \\
\hline ZCS & 680 & 480 \\
\hline ZVZCS & 160 & 180 \\
\hline
\end{tabular}

The efficiency improvement in the ZVZCS mode can be easily identified which is stated in Table 7. As can be seen, the efficiency drop is reduced from $2.30 \%$ in the hard switching mode to $0.23 \%$ in the ZVZCS mode. This signifies an average of $2 \%$ improvement in the efficiency of the converter 
imposed by the ZVZCS operation of the main switch only. Hence, it can be safely concluded that the experimental results are well in accordance with the theoretical claim.

Table 7. Total loss and efficiency drop in $\mathrm{S}_{1}$

\begin{tabular}{|l|c|c|}
\hline Switching mode & $\begin{array}{c}\text { Total switching loss } \\
\text { (turn on + turn off) in } \mathrm{S}_{1} \\
(\mathrm{~mW})\end{array}$ & $\begin{array}{l}\text { Efficiency drop } \\
(\%)\end{array}$ \\
\hline Hard & 3450 & 2.30 \\
\hline ZVS & 1020 & 0.70 \\
\hline ZCS & 320 & 0.78 \\
\hline ZVZCS & 140 & 0.23 \\
\hline
\end{tabular}

he percentage drop in efficiency imposed by the switch $S_{1}$ is measured by varying the switching frequency $\left(f_{s}\right)$ and the input voltage $\left(V_{L}\right)$ at Stage 1, 2 and 3. For this purpose, the $f_{s}$ is varied from 20 $\mathrm{kHz}$ to $150 \mathrm{kHz}$ while $V_{L}$ is kept constant at $80 \mathrm{~V}$ and $P_{O}=150 \mathrm{~W}$. On the other hand, $V_{L}$ is varied from $20 \mathrm{~V}$ to $120 \mathrm{~V}$ while $f_{s}$ is kept constant at $100 \mathrm{kHz}$ and $P_{O}=150 \mathrm{~W}$. The results are demonstrated in Figs. 11 (a) and (b) respectively. As obvious, the efficiency drop in the ZVZCS mode remains consistently lower and is more stable throughout the operating conditions (i.e. variation in $f_{s}$ and $V_{L}$ ). For example, as can be seen in Fig. 11 (a), $\Delta E_{d}=0.2 \%$ and $0.1 \%$ for the ZVS, ZCS and the ZVZCS respectively. Similarly, it is $0.15 \%$ and $0.05 \%$ for the ZVS, ZCS and the ZVZCS respectively as shown in Fig. 11 (b). Consequently, wider soft switching operating range in the ZVZCS mode is ensured.

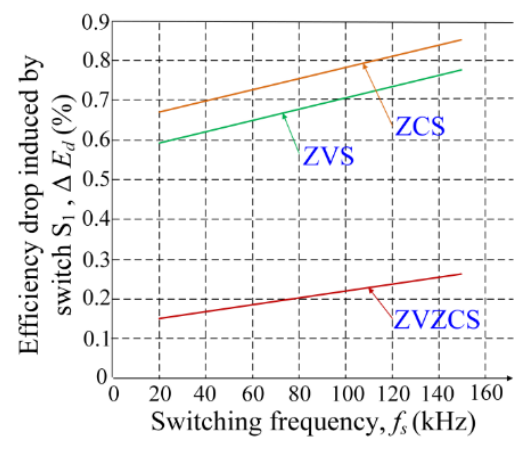

(a)

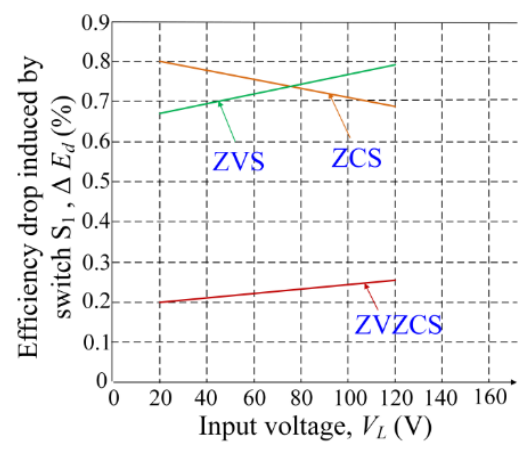

(b)

Figure. 11. Efficiency drop imposed by switch $S_{1}$ against (a) $f_{s}$ (b) $V_{L}$

\section{Discussion}

In this paper, the ZVZCS soft switching technique is analyzed. A theoretical study is provided to demonstrate the superiority of the ZVZCS over the ZVS and the ZCS in reducing the switching losses and improving the soft switching range of operation. It is found that the improvement is primarily because of the ZVZCS not being largely affected by the factors that affect the ZVS turn on (i.e. the input voltage) and the ZCS (i.e. the load current) turn off operations. To support the theoretical claim, a simulation test is performed on several soft switching converters from recent literature. The converters are tested in different operational states to ensure unbiased results. The turn on and turn off losses are then measured in the main switches. It is observed that the induced losses are reduced for the ZVZCS operation which amounts to $26 \%$ and $20 \%$ reduction from the ZVS and the ZCS counterpart respectively. Besides, the low standard deviation (SD) for the ZVZCS operation denotes minimal deviation from the average loss profile throughout the operational states. Thus, a stable low loss profile rendering wider soft switching range is ensured. On top of that, a prototype soft switching converter is built to perform the experimental test. The converter is operable in different soft switching conditions (i.e. the HS, the ZVS, the ZCS, and the ZVZCS) independently. Subsequently, 
the incurred turn on and turns off losses in the main switch are measured under these conditions. Overall, it is observed that the ZVZCS mode reduces the switching losses as compared to the HS, the ZVS or the ZCS and help to improve the converter efficiency further. Moreover, it is found that the efficiency drop remains consistently low and stable while measured against the variation of switching frequency and input voltage. This proves the wider operability of the ZVZCS over the ZVS and the ZCS modes.

Author Contributions: 1. Conceptualization, R H ASHIQUE, Z. SALAM; methodology, R H ASHIQUE.; software, ; validation, R H ASHIQUE, Z. SALAM.; formal analysis, R H ASHIQUE, Z. SALAM; investigation, R H ASHIQUE, Z. SALAM.; resources, R H ASHIQUE, Z. SALAM.; data curation; writing-original draft preparation, R H ASHIQUE; writing-review and editing, $\mathrm{R}$ H ASHIQUE, Z. SALAM.; visualization; supervision, Z. SALAM. All authors have read and agreed to the published version of the manuscript."

Conflicts of Interest: The authors declare no conflict of interest.

\section{References}

[1] W. Chien-Ming, "A New Family of Zero-Current-Switching (ZCS) PWM Converters," IEEE Transactions on Industrial Electronics, vol. 52, pp. 1117-1125, 2005.

[2] M. Mohammadi, E. Adib, and M. R. Yazdani, "Family of Soft-Switching Single-Switch PWM Converters With Lossless Passive Snubber," IEEE Transactions on Industrial Electronics, vol. 62, pp. 3473-3481, 2015.

[3] M. R. Mohammadi and H. Farzanehfard, "A New Family of Zero-Voltage-Transition Nonisolated Bidirectional Converters With Simple Auxiliary Circuit," IEEE Transactions on Industrial Electronics, vol. 63, pp. 1519-1527, 2016.

[4] S. Dusmez, A. Khaligh, and A. Hasanzadeh, "A Zero-Voltage-Transition Bidirectional DC/DC Converter," Industrial Electronics, IEEE Transactions on, vol. 62, pp. 3152-3162, 2015.

[5] T. Mishima and M. Nakaoka, "A Practical ZCS-PWM Boost DC-DC Converter With Clamping Diode-Assisted Active Edge-Resonant Cell and Its Extended Topologies," IEEE Transactions on Industrial Electronics, vol. 60, pp. 2225-2236, 2013.

[6] J. Zhang, J.-S. Lai, R.-Y. Kim, and W. Yu, "High-power density design of a soft-switching high-power bidirectional dc-dc converter," Power Electronics, IEEE Transactions on, vol. 22, pp. 1145$1153,2007$.

[7] R. H. Ashique, Z. Salam, and M. J. A. Aziz, "A high power density soft switching bidirectional converter using unified resonant circuit," in Energy Conversion (CENCON), 2015 IEEE Conference on, 2015, pp. 165-170.

[8] D.-W. Han, H.-J. Lee, S.-C. Shin, J.-G. Kim, Y.-c. Jung, and C.-Y. Won, "A new soft switching ZVT boost converter using auxiliary resonant circuit," in Vehicle Power and Propulsion Conference (VPPC), 2012 IEEE, 2012, pp. 1250-1255.

[9] B. Ivanovic and Z. Stojiljkovic, "A novel active soft switching snubber designed for boost converter," IEEE Transactions on Power Electronics, vol. 19, pp. 658-665, 2004.

[10] T. Mishima and M. Nakaoka, "A new family of soft switching PWM non-isolated DC-DC converters with Active auxiliary Edge-Resonant Cell," in Power Electronics Conference (IPEC), 2010 International, 2010, pp. 2804-2809.

[11] D. Patil, A. K. Rathore, and D. Srinivasan, "A non-isolated bidirectional soft switching current fed LCL resonant dc/dc converter to interface energy storage in DC microgrid," in Applied Power Electronics Conference and Exposition (APEC), 2015 IEEE, 2015, pp. 709-716.

[12] A. K. Rathore, D. R. Patil, and D. Srinivasan, "A Non-Isolated Bidirectional Soft Switching Current fed LCL Resonant DC/DC Converter to Interface Energy Storage in DC Microgrid," Industry Applications, IEEE Transactions on, vol. PP, pp. 1-1, 2015. 
[13] M. Ahmadi, M. R. Mohammadi, E. Adib, and H. Farzanehfard, "Family of non-isolated zero current transition bi-directional converters with one auxiliary switch," IET Power Electronics, vol. 5, pp. 158-165, 2012.

[14] H. Ardi, R. R. Ahrabi, and S. N. Ravadanegh, "Non-isolated bidirectional DC-DC converter analysis and implementation," IET Power Electronics, vol. 7, pp. 3033-3044, 2014.

[15] E. Sanchis-Kilders, A. Ferreres, E. Maset, J. B. Ejea, V. Esteve, J. Jordan, et al., "Bidirectional high-power high-efficiency non-isolated step-up dc-dc converter," in Power Electronics Specialists Conference, 2006. PESC'06. 37th IEEE, 2006, pp. 1-7.

[16] B. Akin, "An Improved ZVT\&\#x2013;ZCT PWM DC\&\#x2013;DC Boost Converter With Increased Efficiency," Power Electronics, IEEE Transactions on, vol. 29, pp. 1919-1926, 2014.

[17] I. Aksoy, H. Bodur, and A. F. Bakan, "A New ZVT-ZCT-PWM DC\&\#x2013;DC Converter," IEEE Transactions on Power Electronics, vol. 25, pp. 2093-2105, 2010.

[18] H. Bodur and A. F. Bakan, "A new ZVT-ZCT-PWM DC-DC converter," Power Electronics, IEEE Transactions on, vol. 19, pp. 676-684, 2004.

[19] H. Bodur and A. F. Bakan, "A new ZVT-ZCT-PWM DC-DC converter," IEEE Transactions on Power Electronics, vol. 19, pp. 676-684, 2004.

[20] C. M. de Oliveira Stein and H. L. Hey, "A true ZCZVT commutation cell for PWM converters," Power Electronics, IEEE Transactions on, vol. 15, pp. 185-193, 2000.

[21] S. Urgun, "Zero-voltage transition\&\#x2013;zero-current transition pulsewidth modulation DC\&\#x2013;DC buck converter with zero-voltage switching\&\#x2023;zero-current switching auxiliary circuit," Power Electronics, IET, vol. 5, pp. 627-634, 2012.

[22] R. H. Ashique and Z. Salam, "A Family of True Zero Voltage Zero Current Switching (ZVZCS) Non-isolated Bidirectional DC-DC Converter with Wide Soft Switching Range," IEEE Transactions on Industrial Electronics, vol. PP, pp. 1-1, 2017.

[23] C. d. O. Stein and H. L. Hey, "A true ZCZVT commutation cell for PWM converters," in Applied Power Electronics Conference and Exposition, 1998. APEC'98. Conference Proceedings 1998., Thirteenth Annual, 1998, pp. 1070-1076.

[24] B. Akın, "An improved ZVT-ZCT PWM DC-DC boost converter with increased efficiency," IEEE Transactions on Power Electronics, vol. 29, pp. 1919-1926, 2014.

[25] I. Aksoy, H. Bodur, and A. F. Bakan, "A new ZVT-ZCT-PWM dc-dc converter," IEEE transactions on power electronics, vol. 25, pp. 2093-2105, 2010. 